\title{
The Effects of Threonine on Performance Parameters, Carcass Traits, Visceral Organ Indices and Serum Biochemical Parameters of Linwu Ducks, Aged 4 to 8 Weeks
}

\section{-Author(s)}

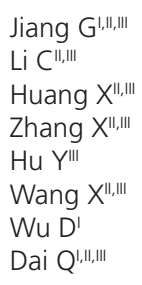

Institute of Bast Fiber Crops, Chinese Academy of Agricultural Sciences, Changsha, 410125, Hunan, P. R. China.

" Hunan Institute of Animal Science and Veterinary Medicine, Changsha, 410131, Hunan, P. R. China.

III Hunan Co-Innovation Center of Animal Production Safety, Changsha 410128, China.

Jiang $\mathrm{G}$ and Li C contributed equally to this work.

\begin{abstract}
This study was conducted to establish dietary threonine (Thr) levels for Linwu ducks, aged 4 to $8 \mathrm{wk}$. Experimental diets formulated to contain $0.56,0.61,0.66,0.71,0.76$, and $0.81 \%$ Thr fed to Linwu ducks. A total of 360 healthy Linwu female ducks with similar body weight $(1183.89 \pm 3.83 \mathrm{~g})$ were randomly divided into six groups, with five replicates in each group, and 12 ducks in each replicate. Samples were collected at $8 \mathrm{wk}$ for the determination of growth performance, carcass traits, visceral organ indices, and serum biochemical parameters. As a result of this study, Thr level had no significant influence on the final weight, the daily gain, feed/gain ratio, and average daily intake $(p>0.05)$. Similarly, there were no significant effects of dietary Thr on carcass traits and visceral organ indices $(p>0.05)$. The pancreatic index was highest among all the treatments when the dietary Thr level was $0.66 \%$. The different dietary Thr levels had no significant effect $(p>0.05)$ on the concentration of total protein (TP), triglyceride $(T G)$, total cholesterol (TC), glucose $(G L U)$, superoxide dismutase (SOD), malondialdehyde (MDA), glutathione peroxidase (GSH-Px), and glutathione $(\mathrm{GSH})$. However, the serum MDA concentration in the $0.66 \%$ treatment was lower $(P=0.068)$ than in the other treatments. In conclusion, Thr at $0.66 \%$ concentration may have an antioxidant activity and exert positive effect on Linwu ducks.
\end{abstract}

\section{INTRODUCTION}

Threonine (Thr) is an essential amino acid in poultry diets. It is the third most limiting amino acid and plays an important role in animal growth and development (Ayasan et al., 2009; Canogullari et al., 2009; Xie et al., 2014). Thr is a typically deficient amino acid in corn, sorghum and soybean meal based rations and it becomes one of the major factors in limiting the birds' performance (Kidd, 2000). Supplementation of Thr in the diets of broiler chicks and white Pekin ducklings was reported to improve their growth performance (Horn et al., 2010; Ayasan \& Okan, 2011). Khan et al. (2006) conducted an experiment on commercial broiler chicks 20 35d of age with different levels of digestible Thr and observed significant improvement in body weight gain. Moreover, Carzo et al. (2009) reported that the whole carcass yield and breast meat were increased with increased Thr in combination with glycine in Ross 308 male broilers. However, Thr did not affect the relative percentages of liver, thigh, and gizzard in Ross 308 broiler chicks (Estalkhzir et al., 2013). Baeza \& Leclercq (1998) designed an experiment to assess the effects of Thr supplementation in finishing diets used for raising Muscovy ducks and found that Thr requirement was greater than $3.5 \mathrm{~g} / \mathrm{kg}$ and less than $4.5 \mathrm{~g} / \mathrm{kg}$.

Linwu duck is a special product in the Linwu County, Hunan province, China. It is one of the most famous ducks in China with characteristics of 
fast growth, large body, strong adaptability, high feed reward, and delicate meat. Currently, the dietary Thr requirement of Linwu ducks has not been determined, and no reference values have been established for animal production. Thus, the objective of the current study was to determine the Thr requirement of Linwu ducks, aged 4 to 8 wk, based on their growth performance, carcass traits, visceral organ indices, and serum biochemical parameters.

\section{MATERIALS AND METHODS}

All the protocols used in the study were approved by the Hunan Institute of Animal Science and Veterinary Medicine Animal Care and Use Committee. (Permit Number: 2017-0306)

\section{Animals and housing}

Three hundred and sixty Linwu ducks (a local breed in southern (hina) were randomly divided into six groups (60 ducks/group) and housed in pens with a plastic floor for 4 wk. Each group had five replicates (12 ducks/pen). The ducks had free access to water and feed. The climatic conditions and lighting program were computer-operated and followed the commercial recommendations. Environmental temperature throughout the period of experiment was $25^{\circ} \mathrm{C}$. During the experimental period, ducks were exposed to natural light-dark cycle.

\section{Experimental diets}

All the feeds were manufactured at the Human Institute of Animal Science and Veterinary Medicine. Basal diet, which was corn and soybean meal based, was formulated to meet the nutrient needs of the Linwu ducks based on the nutrient recommendations of NRC (1994) (Table 1). The Thr content in the basal diet was $0.56 \%$. The other diets consisted of basal diet supplemented with $0.05,0.10,0.15,0.20$, and $0.25 \%$ L-Thr, respectively, so as to have total Thr content of $0.61,0.66,0.71,0.76$, and $0.81 \%$, respectively, in the five experimental diets. The contents of other nutritional ingredients in the diets were the same as in the basal diet.

\section{Growth performance}

The body weight (BW) of ducks in each pen was recorded on a weekly basis from the first to the final day of the experiment. Feed intake in each pen during the period between two consecutive weight determinations was estimated by measuring the remaining feed on the same days on which the ducks
Table 1 - Composition and nutrient levels of the basal diet (air-dry basis)

\begin{tabular}{lc|cc}
\hline Ingredients & Content \% & Nutrient levels ${ }^{2}$ & Content \\
\hline Corn & 46.00 & $\mathrm{ME} / \mathrm{mcal} / \mathrm{kg}$ & 2.75 \\
Soybean meal $(44.0 \% \mathrm{CP})$ & 5.40 & $\mathrm{CP}$ & 16.96 \\
\hline Corn gluten meal(60.0\% CP) & 6.20 & $\mathrm{Ca}$ & 0.88 \\
Cottonseed meal(46.1\% CP) & 5.50 & Total P & 0.71 \\
\hline Wheat bran & 9.30 & $\mathrm{NPP}$ & 0.34 \\
Wheat middling & 10.00 & Lys & 0.91 \\
Rice bran & 8.00 & Met & 0.42 \\
Corn barn & 4.00 & Met+Cys & 0.70 \\
\hline Limestone & 1.45 & Thr & 0.56 \\
CaHPO & 1.20 & Trp & 0.16 \\
Lys & 0.40 & Linoleic acid & 2.03 \\
DL-Met & 0.15 & & \\
NaCl & 0.30 & & \\
Soybean oil & 1.10 & & \\
Premix' & 1.00 & & \\
Total & 100.00 & & \\
\hline
\end{tabular}

${ }^{1}$ The premix provides following for per kg diet: VA 5000 IU, VD 800 IU, VE 20 IU, VK $0.5 \mathrm{IU}$, Niacin $60 \mathrm{mg}$, Pantothenic acid $60 \mathrm{mg}$, Pyridoxine $2.5 \mathrm{mg}$, Riboflavin $4.0 \mathrm{mg}$, Biotin $0.2 \mathrm{mg}$, Folic acid $0.6 \mathrm{mg}$, Thiamine $2 \mathrm{mg}$, Cu $8 \mathrm{mg}$, Fe $80 \mathrm{mg}, \mathrm{Mn} 50 \mathrm{mg}$, Zn 60 $\mathrm{mg}$, Se $0.20 \mathrm{mg}$, and $10.40 \mathrm{mg} .{ }^{2}$ Calculated values.

were weighed. The values of average daily gain (ADG), average daily feed intake (ADFI), and feed:gain ratio $(F / G)$ were calculated as feed per gain based on the weight of feed consumed divided by BW gain per pen.

\section{Sample collection}

At the end of feeding, four ducks were randomly selected from each pen and fasted for $12 \mathrm{~h}$ before sampling. The ducks were euthanized by severing the jugular vein. Each carcass was dissected into deboned skinless thighs and breasts immediately after the slaughter. The weight of each carcass (with feet and head) and its breast fat was recorded. Blood samples were centrifuged at $4000 \times \mathrm{g}$ for $5 \mathrm{~min}$, and serum was separated and packed in tubes. Heart, liver, spleen, pancreas, gizzard, glandular stomach, and bursa of Fabricius were removed, cleaned, and weighed.

\section{Samples analysis}

The concentrations of serum total protein (TP), glucose (GLU), triglyceride (TG), and total cholesterol (TC) were analyzed using an automatic biochemistry analyzer (URIT-8000, USA). Total superoxide dismutase (T-SOD), glutathione peroxidase (GSH-Px), glutathione $(\mathrm{GSH})$, and malondialdehyde (MDA) in the serum were determined using colorimetric methods with a UVvisible spectrophotometer UV-2401PC (Shimadzu Co., Kyoto, Japan). All the serum biochemical parameters were determined by methods of commercial kits that were bought form a commercial company (Jiancheng Bioengineering Institute, Nanjing, China). 


\section{Calculations and statistical analysis}

The different carcass traits and organ index were calculated as follows according to Tong et al (2014): Percentage of eviscerated yield $(\%)=($ eviscerated yield $/$ live-weight) $\times 100$; Percentage of breast $(\%)=($ weight of breast/eviscerated yield) $\times 100$; Percentage of crureus (\%) $=$ (weight of crureus/eviscerated yield $) \times 100$; Percentage of abdominal fat $(\%)=$ (weight of abdominal fat eviscerated yield+weight of abdominal fat) $\times 100$; Organ index $(\%)=$ (weight of organ/live-weight $) \times 100$.

Data were analyzed using the GLM procedure of SPSS 21.0 software (Lu et al. 2000) for one-way ANOVA to assess the main effects of dietary Thr level. Significant differences between the treatments were determined at $p<0.05$ using Duncan's new multiple range tests. The values given in the tables are mean values and pooled SEM.

\section{RESULTS}

\section{Growth performance}

The effects of dietary Thr level on the growth performance of Linwu ducks are presented in Table 2 . There were no significant ( $p>0.05$ ) effects of treatment on the final weight, average daily gain, average daily feed intake, and F/G ratio of animals. However, F/G was gradually reduced with the increase in dietary $T h r$ levels; the value of $F / G$ was minimum when the dietary Thr level was $0.76 \%$.

Table 2 - Effect of dietary Thr level on the growth performance of Linwu ducks, aged 4 to 8 weeks

\begin{tabular}{lcccccccc}
\hline \multirow{2}{*}{ Items } & \multicolumn{9}{c}{ Dietary Thr level (\%) } & \multirow{2}{*}{ SEM } & \multirow{2}{*}{$p$ value } \\
\cline { 2 - 7 } & 0.56 & 0.61 & 0.66 & 0.71 & 0.76 & 0.81 & \\
\hline IW (g) & 1180.33 & 1181.33 & 1187.00 & 1180.00 & 1189.00 & 1185.67 & 8.36 \\
FW (g) & 1513.57 & 1582.43 & 1564.49 & 1565.52 & 1591.68 & 1527.07 & 10.58 & 0.212 \\
ADG (g) & 11.90 & 14.32 & 13.48 & 13.77 & 14.38 & 12.75 & 0.32 & 0.178 \\
ADFI (g) & 129.51 & 123.85 & 116.62 & 114.45 & 111.28 & 121.16 & 2.67 & 0.389 \\
F/G & 11.29 & 8.90 & 8.74 & 8.44 & 7.83 & 9.51 & 0.38 & 0.110 \\
\hline
\end{tabular}

Note: IW=initial weight, FW=final weight, $A D G=$ average daily gain, $A D F I=a v e r a g e$ daily feed intake, and F/G=feed/gain ratio

\section{Carcass traits}

As shown in Table 3, the different carcass traits of Linwu ducks showed no significant difference ( $p>0.05)$ at different dietary Thr levels. However, the dressing percentage and percentage of breast muscle in Linwu ducks was higher $(p>0.05)$ in the treatments in which the dietary Thr level was $0.66 \%$. The percentages of half-eviscerated yield and eviscerated yield were highest when the dietary Thr level was $0.71 \%$.

Table 3 - Effect of dietary Thr level on carcass traits of Linwu ducks, aged 4 to 8 weeks

\begin{tabular}{|c|c|c|c|c|c|c|c|c|}
\hline \multirow{2}{*}{ Items\% } & \multicolumn{6}{|c|}{ Dietary Thr level (\%) } & \multirow{2}{*}{ SEM } & \multirow{2}{*}{$p$ value } \\
\hline & 0.56 & 0.61 & 0.66 & 0.71 & 0.76 & 0.81 & & \\
\hline Dressing percentage & 88.07 & 88.62 & 89.32 & 88.07 & 85.95 & 86.78 & 0.45 & 0.289 \\
\hline Percentage of half-eviscerated yield & 81.09 & 81.41 & 81.11 & 82.22 & 80.02 & 79.55 & 0.42 & 0.504 \\
\hline Percentage of eviscerated yield & 72.93 & 73.19 & 72.75 & 74.05 & 71.64 & 71.78 & 0.40 & 0.543 \\
\hline Percentage of breast muscle & 12.97 & 14.12 & 14.52 & 14.49 & 12.93 & 13.91 & 0.25 & 0.262 \\
\hline Percentage of leg muscle & 9.67 & 10.20 & 11.17 & 9.94 & 10.50 & 11.19 & 0.23 & 0.275 \\
\hline Percentage of abdominal fat & 1.71 & 1.57 & 1.49 & 1.76 & 2.00 & 1.21 & 0.11 & 0.459 \\
\hline
\end{tabular}

\section{Visceral organ indices}

The dietary Thr level had no significant effect ( $p>0.05)$ on the visceral organ indices of Linwu ducks
(Table 4). However, the pancreatic index was highest among all the treatments when the dietary Thr level was $0.66 \%$.

Table 4 - Effect of dietary Thr level on visceral organ indices of Linwu ducks, aged 4 to 8 weeks

\begin{tabular}{|c|c|c|c|c|c|c|c|c|}
\hline \multirow{2}{*}{ Items \% } & \multicolumn{6}{|c|}{ Dietary Thr level (\%) } & \multirow{2}{*}{ SEM } & \multirow{2}{*}{$P$ value } \\
\hline & 0.56 & 0.61 & 0.66 & 0.71 & 0.76 & 0.81 & & \\
\hline Spleen index & 0.60 & 0.65 & 0.61 & 0.63 & 0.59 & 0.58 & 0.03 & 0.847 \\
\hline Pancreatic index & 2.28 & 2.09 & 2.86 & 2.48 & 2.51 & 2.37 & 0.08 & 0.120 \\
\hline Proventriculus index & 2.90 & 3.00 & 3.32 & 2.83 & 2.72 & 3.11 & 0.08 & 0.374 \\
\hline Heart index & 6.85 & 7.45 & 7.45 & 6.73 & 6.86 & 7.49 & 0.13 & 0.278 \\
\hline Liver index & 17.97 & 16.53 & 18.01 & 17.62 & 16.75 & 17.61 & 0.37 & 0.820 \\
\hline Gizzard index & 25.10 & 25.32 & 26.51 & 25.15 & 26.54 & 25.08 & 0.56 & 0.925 \\
\hline
\end{tabular}




\section{Serum biochemical indices}

The dietary Thr level had no significant effect ( $p>0.05)$ on the concentration of TP, TG, GLU, SOD, MDA, GSH-Px, and GSH (Table 5). However, it had significant effect on the concentration of TC, which was highest in the $0.66 \%$ treatment and was significantly higher $(p<0.05)$ than the corresponding value in the $0.81 \%$ treatment. Although there was no significant effect on the concentration of MDA, it was lower $(p=0.068)$ in the $0.66 \%$ treatment compared to that in the other treatments.

Table 5 - Effect of dietary Thr level on serum biochemical indices of Linwu ducks, aged 4 to 8 weeks

\begin{tabular}{|c|c|c|c|c|c|c|c|c|}
\hline \multirow{2}{*}{ Items } & \multicolumn{6}{|c|}{ Dietary Thr level (\%) } & \multirow{2}{*}{ SEM } & \multirow{2}{*}{$p$ value } \\
\hline & 0.56 & 0.61 & 0.66 & 0.71 & 0.76 & 0.81 & & \\
\hline$T P(g / L)$ & 40.80 & 44.20 & 41.00 & 43.20 & 42.60 & 40.80 & 0.91 & 0.863 \\
\hline $\mathrm{TC}(\mathrm{mmol} / \mathrm{L})$ & $5.30^{\mathrm{ab}}$ & $5.96^{a}$ & $6.09^{a}$ & $5.53^{\mathrm{ab}}$ & $5.85^{a}$ & $4.79^{b}$ & 0.13 & 0.016 \\
\hline $\mathrm{TG}(\mathrm{mmol} / \mathrm{L})$ & 0.92 & 0.62 & 0.76 & 0.81 & 0.73 & 0.87 & 0.06 & 0.718 \\
\hline $\mathrm{GLU}(\mathrm{mmol} / \mathrm{L})$ & 9.97 & 11.49 & 11.24 & 9.91 & 10.28 & 9.42 & 0.31 & 0.351 \\
\hline $\mathrm{SOD}(\mathrm{U} / \mathrm{ml})$ & 133.93 & 113.93 & 120.91 & 131.33 & 122.96 & 127.11 & 3.24 & 0.511 \\
\hline $\mathrm{MDA}(\mathrm{nmol} / \mathrm{ml})$ & 5.92 & 6.36 & 5.03 & 5.24 & 7.08 & 6.08 & 0.24 & 0.068 \\
\hline GSH-PX(U/ml) & 494.63 & 459.51 & 438.05 & 481.95 & 479.02 & 459.51 & 9.45 & 0.605 \\
\hline $\mathrm{GSH}(\mu \mathrm{mol} / \mathrm{L})$ & 39.05 & 42.12 & 36.76 & 25.59 & 31.65 & 31.28 & 2.14 & 0.416 \\
\hline
\end{tabular}

Note: in the same row, values with different capital letter superscripts mean significant difference $(p<0.05)$, while with the same or no letter superscripts mean no significant difference $(p>0.05)$.

\section{DISCUSSION}

Thr is the third most limiting amino acid in poultry diets behind the total sulfur-containing amino acids and lysine (Kidd, 2000; Baylan et al., 2006). A suitable amount of Thr in diet can maintain animal health and improve its production. Dietary Thr levels had no significant effect on the feed intake and feed conversion ratio. The results of the present study are in accordance with the study performed on Korean native ducks during 22-56 d with different levels of Thr and observed no significant improvement in body weight gain (Choo et al. 2014). Zhang et al. (2016) carried out an experiment by determining the dietary Thr requirement of Pekin ducks from hatch to $14 \mathrm{~d}$ of age and observed that body weight, body weight gain and feed intake were not significantly affected by increasing dietary Thr. However, Xie et al. (2014) reported that the weight and feed intake of Pekin ducks increased and F/Gratio of ducks decreased linearly or quadratically as the dietary Thr level increased from 5.0 to $8.2 \mathrm{~g} \mathrm{Thr} / \mathrm{kg}$. Similar results were observed by Horn er al. (2009), Jiang et al. (2017) who reported that the growth performance was enhanced when dietary supplementation with Thr in ducks. In addition, Zhang et al. (2014) detected the Thr requirement of Pekin ducks from 15 to $35 \mathrm{~d}$ of age, and reported that the average daily weight gain increased significantly with the dietary Thr concentration. Bi et al. (2012) conducted an experiment on Pekin ducks from hatch to $21 \mathrm{~d}$ with graded concentration of Thr in diets and reported significant improvement with increased dietary Thr levels.

In our study, dietary Thr had no significant effect on the production performance of ducks. This inconsistency in the animal production performance among different studies could be ascribed to the difference in the types of experimental animals, dose of the supplements, and housing environments, and other factors.

Carcass traits are important economic indicators that reflect the meat quality of commercial meat ducks. Several factors have been shown to influence the poultry carcass traits; these include genotype (Kokoszynski et al., 2015), age (Murawska, 2012), dietary energy (Fan et al., 2008), and dietary amino acid (Wang et al., 2004; Tang et al., 2011). Ciftci \& Ceylan (2004) found that breast yield of broiler chickens was increased with the increasing dietary Thr, but abdominal fat was not affected. Similarly, Maqbool (2014) used six Thr levels $(0.48,0.54,0.60,0.61,0.66,0.72$, and $0.78 \%)$ to investigate the effects of dietary $\mathrm{Thr}$ on carcass traits of Pekin ducks from 15 to 35 days of age, and observed that the breast yield was significantly increased at higher Thr levels, but abdominal fat and leg meat yield were not affected. These results are in agreement with the findings of Dozier et al. (2000) who indicated that the total carcass yield and proportions of abdominal fat were not affected by the dietary Thr concentration (in the range from 0.50 to $0.80 \%$ ), but breast fillet weight and its relative yield were maximum at $0.62 \%$ dietary Thr level. The study was performed 
to evaluate the effect of choice feeding based on Thr and observed significant effects on carcass parameters (Ayasan \& Okan, 2014). Our results are in agreement with those of previous studies. Moreover, we observed that the dressing percentage and the percentage of breast muscle were highest at $0.66 \%$ dietary Thr level. Similarly, Bons (2000) reported that the Thr requirement for Pekin ducks from 21 to 49 days was $0.66 \%$, based on the index of percentage of breast muscle.

The feed consumed by animals is digested, absorbed, and utilized for the work performed by the various organs. The development of internal organs is closely linked to growth, development, and health of animals, and to some of their other attributes. Generally, the organ index can reflect the development of organs that is often used in animal nutrition (Steczny et al., 2017). As in the previous study, Azzam \& El-Gogary (2015) found that dietary Thr levels had no significant differences in their effects on the weights of liver, gizzard, and pancreas ( $p>0.05)$. In the present study, the pancreatic, proventriculus, and liver indices were highest at $0.66 \%$ dietary Thr level.

Liver is not only extremely active in oxidizing triglycerides to produce energy, but it can also synthesize large quantities of TC. In the present study, blood TC was highest at $0.66 \%$ dietary Thr level. The reason for this could be that the index of liver was highest at $0.66 \%$ dietary Thr level and it could catabolize large amounts of amino acids. Generally, MDA is used as a biomarker for free radical-induced damage and endogenous lipid peroxidation (Xie et al., 2017). Li et al. (2016) reported that the $0.67 \%$ dietary Thr group had the lowest serum MDA concentration in Xinyang green-shell laying hens. Chen et al. (2017) reported that a higher level of Thr reduced the MDA content in the serum of male broilers $(P=0.012)$. The results from our study indicate that $0.66 \% \mathrm{Thr}$ concentration may have an antioxidant activity and exert a positive effect on animal health.

\section{CONCLUSION}

In conclusion, under the conditions of the present study, the optimum level of Thr in the diet of Linwu ducks, aged 4 to $8 w k$, could improve their performance and played an important role in maintaining their health. However, further research is warranted to confirm these results and to better assess the actual requirement of Thr by Linwu ducks at different stages of life, the information for which is not available from the current literature.

\section{ACKNOWLEDGEMENTS}

The work was supported by the earmarked fund for Modern Agro-industry Technology Research System (CARS-42-21) and the Agricultural Science and Technology Innovation Program (ASTIP), Chinese Academy of Agricultural Sciences. The funders had no role in the study design, data collection and analysis, decision to publish, or preparation of the manuscript.

\section{REFERENCES}

Ayasan T, Okan F, Hizli H. Threonine requirement of broilers from 22 to 42 Days. International Journal of Poultry Science 2009;8(9):862-865.

Ayasan T, Okan F.Threonine requirement of female broilers from 22 to 42 days of age. Süleyman Demirel Üniversitesi Ziraat Fakültesi Dergisi 2011;6(1):15-21.

Ayasan T, Okan F. The Effect of Choice Feeding Based on Threonine on Performance and Carcass Parameters of Male Broiler Chicks. Turkish Journal of Agriculture-Food Science and Technology 2014;2(4):190196.

Azzam MMM, El-Gogary MR. Effects of dietary threonine levels and stocking density on the performance, metabolic status and immunity of broiler chickens. Asian Journal of Animal and Veterinary Advances 2015; 10(5):215-225.

Baeza E, Leclerca B. Use of industrial amino acids to allow low protein concentrations in finishing diets for growing Muscovy ducks. British Poultry Science 1998;39(1):90-96.

Baylan M, Canogullari S, Ayasan T, Sahin A. Dietary threonine supplementation for improving growth performance and edible carcass parts in Japanese Quails, Coturnix coturnix japonica. International Journal of Poultry Science 2006;5(7):635-638.

Bi Y, Nan XM, Zheng SS, Jiang LS, Xiong BH. Effects of dietary threonine and immune stress on growth performance, carcass trait, serum immune parameters, and intestinal muc2 and NF-êb gene expression in Pekin ducks from hatch to 21 days. Poultry Science 2017;97(1):177-187.

Bons A.The requirement of amino acid for Pekin ducks from twenty one to forty nine days old. Animal Production 2000;38(2):257-262.

Canogullari S, Baylan M, Ayasan T. Threonine requirement of laying Japanese Quails. Journal of Animal and Veterinary Advances 2009;8(8):15391541.

Carzo A, Kid MT, Dozier III WA, Kerr BJ. Dietary glysine and threonine interactive effects in broilers. Journal of Applied Poultry Research 2009;18(1):79-84.

Chen YP, Cheng YF, Li XH, Yang WL, Wen C, Zhuang S, et al. Effects of threonine supplementation on the growth performance, immunity, oxidative status, intestinal integrity, and barrier function of broilers at the early age. Poultry Science 2017;96(2):405-413.

Choo YK, Kwon HJ, Oh ST, Kang CW, Kim HK, et al. Growth performance and carcass characteristics of Korean native ducks fed diets with varying levels of limiting amino acids. Asian-Australasian Journal of Animal Sciences 2014;27(4):518-523.

Ciftci I, Ceylan N. Effects of dietary threonine and crude protein on growth performance, carcase and meat composition of broiler chickens. British Poultry Science 2004;45(2):280-289. 
Jiang $G$, Li C, Huang $X$, Zhang $X$, Hu Y, Wang X, Wu D, Dai Q
The Effects of Threonine on Performance Parameters,

Carcass Traits, Visceral Organ Indices and Serum Biochemical Parameters of Linwu Ducks, Aged 4 to 8 Weeks

Murawska D. The effect of age on the growth rate of tissues and organs and the percentage content of edible and nonedible carcass components in Pekin ducks. Poultry Science 2012;91(8):2030-2038.

NRC. Nutrient requirements of poultry. $9^{\text {th }}$ ed. Washington: National Research Council;1994.

Steczny K, Kokoszynski D, Bernacki Z, Wasilewski R, Saleh M. Growth performance, body measurements, carcass composition and some internal organ characteristics in young Pekin ducks. South African Journal Animal Science 2017;47(3):399-406.

Tang XY, Gao JS, Yuan F, Zhang WX, Shao YJ, Sakurai F, et al. Effects of Sophy beta-glucan on growth performance, carcass traits, meat composition, and immunological responses of Peking ducks. Poultry Science 2011;90(4):737-745.

Tong HB, Wang Q, Lu J, Zou JM, Chang LL, Fu SY. Effect of free-range days on a local chicken breed:Growth performance, carcass yield, meat quality, and lymphoid organ index. Poultry Science 2014;93(8):18831889.

Wang $Y Z, X u Z R$, Feng J. The effect of betaine and DL-methionine on growth performance and carcass characteristics in meat ducks. Animal Feed Science and Technology 2004;116(1-2):151-159.

Xie M, Zhang L, Wen ZG, Tang J, Huang W, Hou SS. Threonine requirement of White Pekin ducks from hatch to $21 \mathrm{~d}$ of age. British Poultry Science 2014;55(4):553-557.

Xie SW, Tian LX, Niu J, Liang GY, Liu YJ. Effect of N-acetyl cysteine and glycine supplementation on growth performance, glutathione synthesis, and antioxidative ability of grass carp, Ctenopharyngodon idella. Fish Physiology and Biochemistry 2017;43(4):1011-1020.

Zhang Q, Xu L, Doster A, Murdoch R, Cotter P, Gardner A, et al. Dietary threonine requirement of Pekin ducks from 15 to 35 days of age based on performance, yield, serum natural antibodies, and intestinal mucin secretion. Poultry Science 2014;93(8):1972-1980.

Zhang Q, Zeng QF, Cotter P, Applegate TJ. Dietary threonine response of Pekin ducks from hatch to $14 \mathrm{~d}$ of age based on performance, serology, and intestinal mucin secretion, Poultry Science 2016;95(6):1348-1355. 